\title{
Impaired knowledge in individuals with heart failure: a middle range nursing theory
}

\author{
Conhecimento deficiente em indivíduos com insuficiência cardíaca: uma teoria de enfermagem de médio alcance
}

Conocimiento deficiente en individuos con insuficiencia cardíaca: una teoría de enfermería de mediano alcance

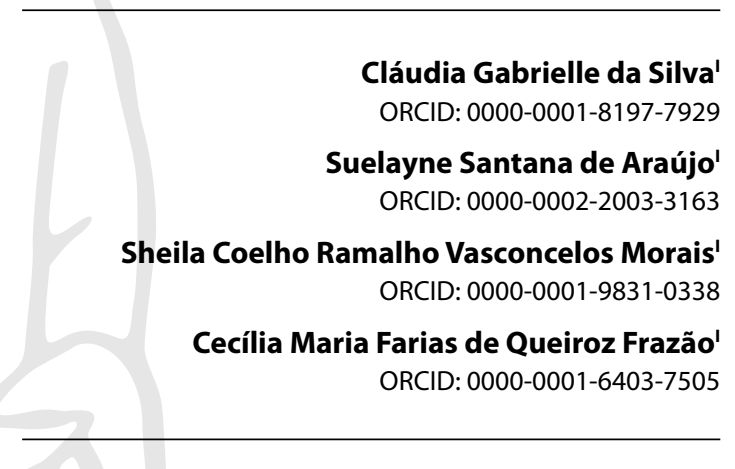

'Universidade Federal de Pernambuco. Recife, Pernambuco, Brazil.

How to cite this article: Silva CG, Araújo SS, Morais SCRV, Frazão CMFQ. Impaired knowledge in individuals with heart failure: a middle range nursing theory. Rev Bras Enferm. 2022;75(2):e20200855. https://doi.org/10.1590/0034-7167-2020-0855

Corresponding author:

Cláudia Gabrielle da Silva

E-mail:cgsgabrielle@gmail.com

EDITOR IN CHIEF: Antonio José de Almeida Filho ASSOCIATE EDITOR: Margarida Vieira

Submission: 09-14-2020

Approval: 06-10-2021

\begin{abstract}
Objective: To develop a middle range nursing theory of impaired knowledge in individuals with heart failure. Methods: Descriptive study of the cross type developed through the theoretical-causal validity method, which used six steps for theory building: Definition of the construction approach; Definition of theoretical-conceptual models; Definition of main concepts; Development of a pictorial scheme; Construction of propositions; and Establishment of causal relations and evidence for practice. Results: Twenty-four articles were found, which identified two attributes, eight antecedents, and seven consequences, which gave rise to the pictogram, which schematized the concepts by relating them to cardiac physiology. Finally, 11 propositions and four causal relationships were created. Conclusion: The constructed theory enables a targeted driving of nurses'clinical judgment regarding impaired knowledge in individuals with heart failure, culminating in individualized interventions to improve quality of life.

Descriptors: Knowledge; Nursing Care; Heart Failure; Nursing Diagnosis; Nursing Theory.
\end{abstract}

\section{RESUMO}

Objetivo: Desenvolver uma teoria de enfermagem de médio alcance sobre o conhecimento deficiente em indivíduos com insuficiência cardíaca. Métodos: Estudo descritivo do tipo transversal desenvolvido por meio do método de validade teórico-causal, que utilizou para a construção da teoria seis etapas: Definição da abordagem de construção; Definição dos modelos teórico-conceituais; Definição dos conceitos principais; Desenvolvimento de um esquema pictorial; Construção das proposições; e Estabelecimento das relações de causalidade e de evidências para a prática. Resultados: Foram encontrados 24 artigos, que identificaram dois atributos, oito antecedentes e sete consequentes, os quais deram origem ao pictograma, que esquematizou os conceitos relacionando-os com a fisiologia cardíaca. Por fim, 11 proposições e 4 relações de causalidade foram criadas. Conclusão: A teoria construída possibilita uma condução direcionada do julgamento clínico dos enfermeiros em relação ao conhecimento deficiente em indivíduos com insuficiência cardíaca, culminando em intervenções individualizadas a fim de melhorar a qualidade de vida.

Descritores: Conhecimento; Cuidados de Enfermagem; Insuficiência Cardíaca; Diagnóstico de Enfermagem; Teoria de Enfermagem.

\section{RESUMEN}

Objetivo: Desarrollar teoría de enfermería de mediano alcance acerca del conocimiento deficiente en individuos con insuficiencia cardíaca. Métodos: Estudio descriptivo del tipo transversal desarrollado por medio del método de validez teórico-causal, que utilizó para la construcción de la teoría seis etapas: Definición de abordaje de construcción; Definición de los modelos teórico-conceptuales; Definición de los conceptos principales; Desarrollo de un esquema pictorial; Construcción de las proposiciones; y Establecimiento de las relaciones de causalidad y de evidencias para la práctica. Resultados: Fueron encontrados 24 artículos, que identificaron dos atributos, ocho antecedentes y siete consecuentes, los cuales originaron el pictograma, que esquematizó los conceptos relacionándolos a fisiología cardíaca. Por fin, 11 proposiciones y 4 relaciones de causalidad fueron creadas. Conclusión: La teoría construida posibilita una conducción dirigida del juicio clínico de los enfermeros en relación al conocimiento deficiente en individuos con insuficiencia cardíaca, culminando en intervenciones individualizadas a fin de mejorar la calidad de vida.

Descriptores: Conocimiento; Atención de Enfermería; Insuficiencia Cardíaca; Diagnóstico de Enfermería; Teoría de Enfermería. 


\section{INTRODUCTION}

Heart failure (HF) is pointed out as a major public health problem, since approximately 23 million people are diagnosed and 2 million cases occur worldwide every year ${ }^{(1)}$. It is characterized by a clinical syndrome, generally progressive and irreversible, caused by functional and/or structural injury of the ventricular filling or of the ejection fraction of the heart, which favors the appearance of signs and symptoms that limit the execution of the daily activities of the individuals $s^{(1-2)}$.

A multicenter study conducted in all regions of Brazil revealed the main causes for decompensation in individuals with HF, namely: poor medication compliance, infections and inadequate control of fluid/sodium intake. In addition, it found that about $60 \%$ of patients received guidance at hospital discharge regarding drug therapy, 40\% regarding diet, and $20 \%$ regarding physical activity ${ }^{(3)}$.

It is a fact that knowledge on the part of patients and caregivers/family members has a positive impact on therapeutic adherence. On the other hand, the deficit of knowledge about the peculiarities of HF and the importance of continuity of the therapeutic regimen by those involved can increase the morbidity and mortality rates of this population ${ }^{(3)}$. Thus, understanding the phenomenon of impaired cognition in individuals with heart failure allows nurses to carry out a clinical judgment to develop a therapeutic plan directed to the real needs of each person.

The understanding of a nursing phenomenon can be achieved through the development of nursing theories ${ }^{(4)}$, which are concepts planned and communicated from reality, with the aim of describing, predicting and prescribing nursing care, as well as contributing to the development of knowledge and strengthened practice ${ }^{(5-6)}$. In this context, the middle range theories are found (MRTs).

MRTs is defined as a set of concepts focused on a limited reality of practice, being less abstract than major theories and can be developed by means of a major theory, such as the Sister Callista Roy Adaptation Model. This has elements that clarify the way of adaptation of patients facing a diagnosis of chronic diseases, allowing the implementation of qualified nursing care directed to promote the adaptation of these patients to new conditions of health and disease ${ }^{(5)}$.

That said, defining the theoretical model to be analyzed is an essential step for there to be congruence between common propositions and concepts. Thus, it becomes possible to identify the etiological elements and clinical characteristics, establishing the causal relationships that explain a given human response ${ }^{(4)}$.

\section{OBJECTIVE}

To develop a middle range nursing theory of impaired knowledge in individuals with heart failure.

\section{METHODS}

\section{Ethical aspects}

This study was approved by the Research Ethics Committee of the Universidad Federal de Pernambuco.

\section{Design, place of study and period}

This is a descriptive, cross-sectional study supported by the causal theoretical validity method, established by Lopes and Silva ${ }^{(4)}$. This contribution is part of the first of three stages of the advanced method for validating nursing diagnoses, namely: theoretical-causal validity, content validity, and clinical validity.

The literature search took place between August and September 2018, through the CAPES Journals Portal. The databases selected were: Cumulative Index to Nursing \& Allied Health Literature (CINAHL), Latin American and Caribbean Literature on Health Sciences (LILACS), National Library of Medicine and National Institutes of Health (MEDLINE/PubMed), and Scopus.

\section{Population or sample; inclusion and exclusion criteria}

Inclusion criteria were: free full articles available in the selected databases in the last ten years (2008-2018); articles available in Portuguese, English or Spanish languages; studies addressing one or more of the items "essential attributes of impaired knowledge" and/or "clinical antecedents and consequences of impaired knowledge"; and heart failure patients. The exclusion criteria were: editorials, letters to the editor, abstracts, and integrative literature reviews.

The descriptors used in Portuguese were "heart failure","nursing care" and "knowledge", being confirmed in Health Sciences (DeCS) and used in the LILACS base. The words used in English, from Medical Subject Headings (MeSH), were: "heart failure", "knowledge" and "nursing care", being used in MEDLINE/PubMed, Scopus and CINAHL. The following cross-references were performed: heart failure AND knowledge; heart failure AND nursing care; heart failure AND knowledge AND nursing care.

\section{Study protocol}

In the development of MRTs, we went through six steps proposed by Lopes and Silva ${ }^{(4)}$ : Definition of the MRTs construction approach; Definition of the theoretical-conceptual models to be analyzed; Definition of the main MRTs concepts; Development of a pictorial scheme; Construction of MRTs propositions; and Establishment of causal relationships and evidence for practice.

In the MRTs construction approach, an integrative review (IR) was conducted, which had as guiding questions: What are the essential attributes of impaired knowledge in patients with heart failure? What are the antecedents and consequences of impaired knowledge in patients with heart failure?

Such questions were constructed based on the concept analysis approach proposed by Walker and Avant, which has as one of its goals: to provide an understanding of the attributes of a concept and to identify antecedents (incidents that precede the occurrence of the concept) and consequences (events that result from the occurrence of the concept) to further refine the definitions of the attributes ${ }^{(7)}$.

In the next step of MRTs construction, the Sister Callista Roy Adaptation Model was defined to assist in developing the propositions and causality relationships of the concepts identified in the IR with the concepts of the chosen theoretical model.- 
Roy defines the individual as a holistic adaptive system that has inputs, outputs, and controls, triggering responses depending on the stimulus received. Input through stimuli activates cognitive and regulatory mechanisms that aim to maintain adaptation. Outputs are the adaptive responses that people make to themselves and to the environment ${ }^{(5)}$.

In the third step, the main concepts of MRTs were identified through the identification of attributes, antecedents, and consequences. Furthermore, there was an association with the concepts of stimulus and behavior from Roy's Model ${ }^{(5)}$.

In the subsequent step, for the development of a pictorial scheme, a figure was elaborated that contemplated the elements of the MRTs, with equivalence to the concepts of Roy's Adaptation Model and the functioning of the heart (Figure 1). The pictogram is a graphic representation of the MRTs and its elements, in a summarized form ${ }^{(4)}$.

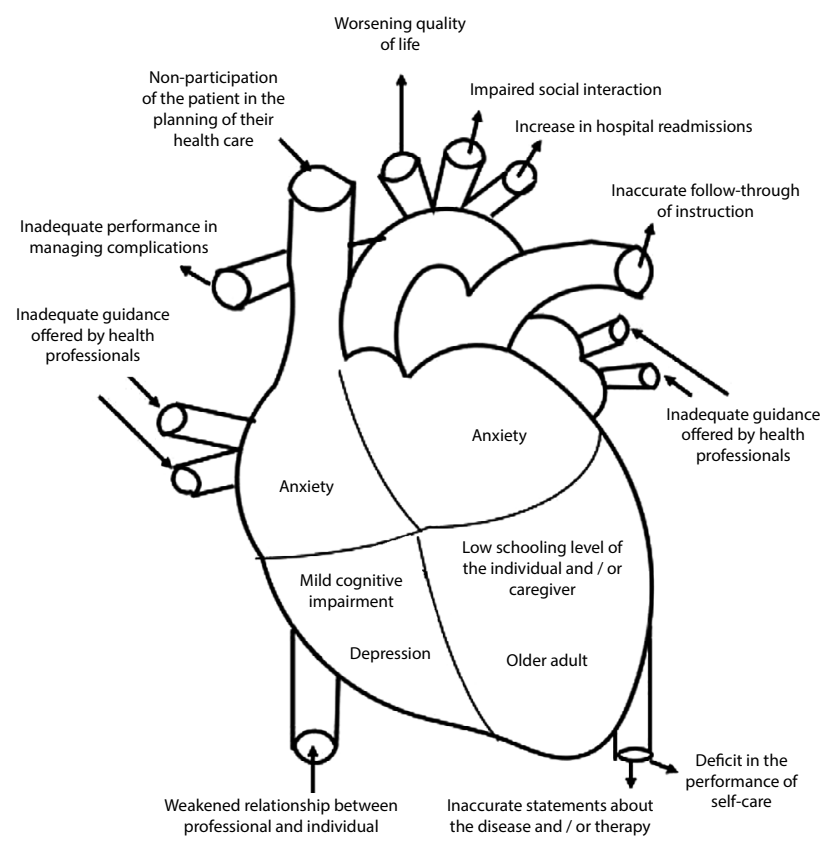

Figure 1 - Explanatory pictogram with the interrelation of the concepts of impaired knowledge in patients with heart failure, Recife, Pernambuco, Brazil, 2019

In the fifth and sixth stages, propositions and causal relationships were constructed by forming assertive and causal statements (the clinical relationships that will allow one to conduct logical and verifiable clinical reasoning and judgment) ${ }^{(4)}$ between the elements contemplated in MRTs and the concepts of the Sister Callista Roy Adaptation Model.

\section{Analysis of results and statistics}

The data found in the IR were analyzed descriptively, enabling the identification of concepts to understand attributes, antecedents and consequences. That said, the equivalence of the MRTs elements with the components of the nursing diagnosis was established. That is, the essential attributes made up the definition of the diagnosis; antecedents were categorized into related factors, associated conditions, and populations at risk; and the consequents formed the defining characteristics.

\section{RESULTS}

A total of 7,979 studies were found, of which 64 belonged to LILACS, 823 to CINAHL, 2,487 to MEDLINE/PubMed, and 4,605 to Scopus. Of the total, 159 articles were selected by title; of these, after reading the abstract, 105 were excluded, leaving 54 articles to be read in full. After this process, 24 articles were selected for evaluation, analysis/interpretation, and synthesis of knowledge.

The evaluation of the 24 articles occurred with the categorization in relation to the countries that were developed, year of publication and level of evidence proposed by Melnyk and Fineout-Overholt ${ }^{(8)}$.

The articles originated mainly from Brazil (41.66\%), followed by the United States (33.33\%), released between the years 2013 to 2018 (79.16\%). As for the level of evidence, most (50\%) were classified as level II, with a predominance of experimental studies $(n=12)$.

The knowledge analysis/interpretation and synthesis of the articles was performed by identifying essential attributes, antecedents, and consequences of impaired knowledge of heart failure patients, as shown in Chart 1.

Chart 1 - Essential attributes, antecedents and consequences of impaired knowledge in patients with heart failure, Recife, Pernambuco, Brazil, 2019

\begin{tabular}{|l|}
\hline Attributes \\
\hline Inadequate information \\
\hline Vague answers to questions \\
\hline Consequences \\
\hline \multicolumn{1}{|c|}{ Increased hospital readmissions } \\
\hline \multicolumn{1}{|c|}{ Inaccurate statements about the disease and/or therapy } \\
\hline \multicolumn{1}{|c|}{ Inadequate performance in the management of complications } \\
\hline Inadequate instructional follow-up \\
\hline Antecedents \\
\hline Anxiety \\
\hline Low education of the individual and/or caregiver \\
\hline Mild cognitive impairment \\
\hline Depression \\
\hline Elderly \\
\hline Non-participation of the patient in health care planning \\
\hline Inadequate orientation offered by health professionals \\
\hline Weakened relationship between professional and individual \\
\hline
\end{tabular}

With this, the elements were defined conceptually and operationally; and the antecedents and consequences were associated with the concepts used by Callista Roy in her Adaptation model - stimuli and behaviors, respectively.

The antecedents were organized according to the classification of the stimuli, as follows: 1) Focal stimuli - Inadequate guidance offered by professionals, Lack of patient participation in health 
care planning, and Weakened relationship between professional and individual; 2) Contextual stimulus - Anxiety; 3) Residual stimuli - Low education of the individual and/or caregiver, Elderly, Mild cognitive impairment, and Depression.

The pictogram was constructed to elucidate the association of the elements of MRT (antecedents and consequences) with the concepts of Roy's Adaptation Model (stimuli and behaviors). The heart shape with its input pathways (superior and inferior vena cava and pulmonary veins) and outputs (pulmonary arteries; aorta artery) represents the stimuli received and the behaviors generated by the stimuli, respectively (Figure 1).

Subsequently, 11 propositions were developed by forming a statement with the involvement of the attributes, antecedents, and consequences found in the HF and concepts used by Callista Roy in her adaptation model (Chart 2).
Finally, the four causal relations were built establishing the event of the adaptive problem "impaired knowledge" by the focal and contextual/antecedent stimuli listed by MRT, allowing conducting clinical reasoning and judgment, as shown in Chart 3.

\section{DISCUSSION}

The MRT construction approach used as strategy reviews of HF type studies, according to the methods for validation proposed by Lopes and Silva ${ }^{(4)}$. The content of the final sample of 24 articles allowed the identification of the attributes, antecedents and consequences of the phenomenon "impaired knowledge in individuals with heart failure", associating them to the concepts of stimulus (focal, contextual and residual) and behavior, used by Roy in his theoretical model(5).

Chart 2 - Proposals with the interrelation of the concepts of the Middle Range Theory of impaired knowledge in Individuals with Heart Failure, Recife, Pernambuco, Brazil, 2019

\begin{tabular}{|l|}
\hline Propositions for the antecedents \\
\hline $\begin{array}{l}\text { From the moment the individual is not invited to elaborate his/her care plan together with the team, he/she becomes a passive agent, so that his/ } \\
\text { her understanding may be compromised and become a focal stimulus for the appearance of a deficient knowledge related to heart failure. }\end{array}$ \\
\hline $\begin{array}{l}\text { Inadequate guidance offered by health professionals is a stimulus that directly affects the heart failure patient, perpetuating the adaptive problem } \\
\text { "decrease in cognitive process". }\end{array}$ \\
$\begin{array}{l}\text { Vague responses to questioning and/or inadequate information regarding heart failure are found among patients who have a weakened } \\
\text { relationship with health care professionals. }\end{array}$ \\
\hline $\begin{array}{l}\text { Sociodemographic (age and low education) and clinical factors (anxiety, depression, and mild cognitive impairment) are triggers that are present in } \\
\text { patients who have vague answers to questions and/or inadequate information regarding heart failure. }\end{array}$ \\
\hline Propositions for consequences \\
\hline One of the factors leading to increased hospital readmissions among patients with heart failure is impaired knowledge about their disease and therapy. \\
\hline The individual with heart failure will have a self-care deficit behavior that will be greater the less knowledge he/she has about the disease. \\
\hline Decreased cognitive process interferes with decision making in the face of an intercurrence. \\
\hline Impaired knowledge about heart failure leads to patient behaviors: for example, impaired social interaction. \\
\hline The worsening in the quality of life of patients with heart failure who also have the adaptive problem "decreased cognitive process" is noticeable. \\
\hline $\begin{array}{l}\text { Inadequate follow-up instruction is a behavior present in patients who reported vague answers to questions and/or inadequate information } \\
\text { regarding heart failure. }\end{array}$ \\
\hline $\begin{array}{l}\text { Inaccurate statements about disease and/or therapy are issued by patients with heart failure when they have the adaptive problem "decreased } \\
\text { cognitive process". }\end{array}$ \\
\hline
\end{tabular}

Chart 3 - Relationships of the concepts of the Middle Range Theory of Impaired Knowledge in Individuals with Heart Failure, Recife, Pernambuco, Brazil, 2019

\begin{tabular}{|l|}
\hline Causal relations of impaired knowledge \\
\hline Focal Stimuli \\
\hline $\begin{array}{l}\text { Inadequate orientation offered by health professionals can lead to impaired knowledge for the adequate performance in the management of } \\
\text { intercurrences. }\end{array}$ \\
\hline $\begin{array}{l}\text { A weakened relationship between professional and individual may contribute to the appearance of inaccurate statements about the disease and/or } \\
\text { therapy due to impaired knowledge. }\end{array}$ \\
\hline Impaired knowledge can be associated with patients' non-participation in their health care planning, evidencing an increase in hospital readmissions. \\
\hline The patient's non-participation in his or her health care planning can generate anxiety and result in deficits in self-care performance. \\
\hline Contextual stimuli \\
\hline Anxiety is a condition that can arise in response to inadequate guidance offered by health professionals, perpetuating a deficit in self-care performance. \\
\hline Residual stimuli \\
\hline $\begin{array}{l}\text { Mild cognitive impairment and low education of the individual and/or caregiver may be responsible for inaccurate statements about the disease } \\
\text { and/or therapy, evidencing impaired knowledge. }\end{array}$ \\
\hline $\begin{array}{l}\text { Depression may start after a new clinical condition and be responsible for inadequate instructional follow-up and self-care deficits, demonstrating } \\
\text { impaired knowledge. }\end{array}$ \\
\hline
\end{tabular}


The major theories, by presenting global perspectives, guide the construction of an MRT, such as Roy's Adaptation Model ${ }^{(5)}$. In addition, this Model has been found to be one of the most widely used for the development of Middle Range Theories in primary Brazilian nursing studies ${ }^{(9)}$.

As advocated by Callista Roy, theories can be developed from existing research, becoming evidence for practice. Thus, the antecedents were classified in focal stimuli (Inadequate guidance offered by health professionals; Non-participation of the patient in planning their health care; and Weak relationship between professional and individual), contextual (Anxiety) and residual (Low education of the individual and/or caregiver; Elderly; Mild cognitive impairment; and Depression) ${ }^{(5)}$.

Studies conducted with individuals with HF have shown that some guidelines are not referred to by the health care team, or understood by individuals, which leads them to an ineffective performance when facing signs and symptoms of the disease ${ }^{(10)}$.

Another stimulus evidenced, the fragility in the relationship between professional and individual, can influence the assistance and, thus, interfere negatively in the relationship, weaken the professional-patient bond and impair the patient's participation in the planning of his/her care ${ }^{(11)}$.

Low education and advanced age are conditions that affect individuals' appropriate knowledge about their disease ${ }^{(10)}$, the former condition also interferes with treatment adherence and hospital readmissions ${ }^{(12)}$. Also, mild cognitive impairment as well as depression and anxiety were responsible for decreased selfcare leading to increased readmissions ${ }^{(13)}$.

The way individuals respond to stimuli characterizes their behavior, which is the "output" of the human system responsible for generating feedbacks through adaptive or ineffective responses ${ }^{(5)}$. The focal stimulus is the one that impacts individuals the most, and is thus immediately confronted by them. The contextual is the behavior developed by the individual in response to the focal stimulus. Finally, the residual stimuli are found in the environment, but the person is not aware of their existence, and the impact they have on behavior is still unknown ${ }^{(5)}$.

The consequence elements had equivalence with the behaviors presented by individuals with HF on the phenomenon "impaired knowledge", namely: Increased hospital readmissions; Inaccurate statements about disease and/or therapy; Deficit in self-care performance; Inadequate performance in the management of intercurrences; Impaired social interaction; Worsening quality of life; and Inadequate instructional follow-up.

In addition to the association with Roy's Model concepts, the antecedent and consequence elements along with the attributes were defined in a conceptual and operational manner to clarify the clinical meaning and base the construction of the pictogram ${ }^{(4)}$.
Then, the pictorial scheme, propositions, and causal relations were built in parallel, based on the Adaptation Model. In addition to the pictogram, the cardiac physiology mechanism was used to clarify the association of the elements, which, under normal conditions, involves the entry ways (superior and inferior vena cava), responsible for the transport of venous blood from the body to the heart, causing the first impact, the arrival of blood to the heart with the increase of right atrial pressure ${ }^{(2)}$.

Causality relationships are the clinical relationships that will enable logical and verifiable clinical reasoning and judgment. Both are guiding elements for the practical implementation of $\mathrm{MRT}^{(4)}$. In this study, 11 propositions were developed and four causal relations were established.

With this, it becomes evident that causal relationships allow clinical reasoning and judgment to proceed ${ }^{(4)}$. Therefore, as one has knowledge and understands what is taught, the information flows and the orientation is followed, culminating in the maintenance of quality of life. However, when stimuli influence in a non-positive way - for example, when the orientation offered by health professionals is inadequate - a picture of instability can begin, that is, a deficient knowledge.

\section{Study limitations}

One limitation was the small number of studies for extracting the main concepts for MRT on impaired knowledge in individuals with heart failure.

\section{Contributions to nursing, health care, or public policy}

The construction of MRT allowed the development of a theoretical contribution about the deficient knowledge in patients with $\mathrm{HF}$, which can help nurses in their clinical judgment and support new studies that can significantly contribute to the care practice.

\section{CONCLUSION}

The study developed a Middle Range Nursing Theory of Impaired Knowledge in individuals with heart failure, drawing on the theoretical framework of Callista Roy's Adaptation Model.

The MRT on the deficient knowledge in individuals with heart failure presented 2 attributes, 7 consequences, 8 antecedents, 11 propositions and 4 causal relations, as well as an explanatory pictogram with the interrelationship between the concepts and cardiac physiology. Moreover, the theoretical support built allows a conduction of reasoning and clinical judgment of nurses in their practical performance in relation to the target audience, guiding them in carrying out interventions according to the individual demand of patients in order to promote improvement and/or maintenance of quality of life.

\section{REFERENCES}

1. Azevedo PR, Sousa MM, Oliveira JS, Freire MEM, Matos SDO, Oliveira SHS. Conocimiento de los enfermeros sobre la insuficiencia cardíaca: un estudio comparativo. Enferm Glob. 201817(2):30-4. https://doi.org/10.6018/eglobal.17.2.289391

2. Woods SL, Froelicher ESS, Motzer SA. Enfermagem em cardiologia. São Paulo: Manole; 2005. 
3. Albuquerque DC, Souza Neto JD, Bacal F, Rohde LEP, Bernadez-Pereira S, Berwanger O, et al. I Brazilian Registry of Heart Failure: clinical aspects, care quality and hospitalization outcomes. Arq Bras Cardiol. 2014;104(6):433-42. https://doi.org/10.5935/abc.20150031

4. Lopes MVO, Silva VM. Métodos avançados de validação de diagnósticos de enfermagem. In: PRONANDA: programa de atualização em diagnósticos de enfermagem: conceitos básicos. Porto Alegre: Artmed; 2016. p. 9-51.

5. Roy SC. The Roy adaptation model. In: Masters K. Nursing theories: a framework for professional practice. New Jersey: Pearson Education; 2009. p. 128-33.

6. Medeiros LP, Souza MBC, Sena JF, Melo MDM, Costa JWS, Costa IKF. [Roy Adaptation Model: integrative review of studies conducted in the light of the theory]. Rev Rene 2015;16(1):132-40. https://doi.org/10.15253/2175-6783.2015000100017 Portuguese.

7. Walker LO, Avant KC. Strategies for theory construction in nursing. New Jersey: Pearson/Prentice Hall; 2011.

8. Melnyk BM, Fineout-Overholt E. Evidence-based practice in nursing and healthcare: a guide to best practice. Philadelphia: Lippincott Williams \& Wilkins; 2010.

9. Tonin L, Batista J, Lacerda MR, Cruz EDA, Mantovani MF, Nascimento JD. References used in the meiddle ranger nursing theories: integrative review. Adv Nurs Health. 2019;1:23-33. https://doi.org/10.5433/anh.2019v1.id38066

10. Zeng W, Chia SY, Chan YH, Tan SC, Low EJH, Fong MK. Factors impacting heart failure patients" knowledge of heart disease and self-care management. Proc Singap Healthc. 2017;26(1):26-34. https://doi.org/10.1177/2010105816664537

11. Altenhofen V, Castro EK. A percepção da doença cardíaca e da comunicação do diagnóstico. Psicol Saude Doencas. 2018;19(3):515-25. https://doi.org/10.15309/18psd19030104

12. Bonin CDB, Santos RZ, Erkmann N, Souza VF, Assis AV, Benetti M. Knowledge about heart failure in participants and non-participants cardiac rehabilitation. Int J Cardiovasc Sci. 2016;29(6):453-9. https://doi.org/10.5935/2359-4802.20170001

13. Hwang B, Moser DK, Dracup K. Knowledge is insufficient for self-care among heart failure patients with psychological distress. Health Psychol. 2014;33(7)588-96. https://doi.org/10.1037/a0033419 